\title{
Effects of Diabetes Numeracy on Glycemic Control and Diabetes Self-Management Behaviors in Patients on Insulin Pump Therapy
}

Kali B. Turrin · Jennifer M. Trujillo

Received: July 6, 2018 / Published online: May 30, 2019

(c) The Author(s) 2019

\section{ABSTRACT}

Introduction: Diabetes numeracy (DN) skills are crucial in patients on insulin pump therapy. Little evidence exists regarding $\mathrm{DN}$ in this patient population.

Methods: This exploratory, observational, cross-sectional study assessed the DN levels of patients on insulin pump therapy and potential relationships with glycemic control and self-management behaviors. Seventy-two patients on insulin pump therapy were recruited from one specialty endocrinology clinic. Subjects completed validated tools to measure DN [Diabetes Numeracy Test (DNT15)] and self-management behaviors [Diabetes Self-Management Questionnaire (DSMQ)]. A general diabetes questionnaire assessed socioeconomic information and self-efficacy. Additional self-management behaviors and glycemic control data were collected from patients' medical records. Patients were categorized into two groups based on DNT-15 scores to explore potential relationships

Enhanced Digital Features To view enhanced digital features for this article go to https://doi.org/10.6084/ m9.figshare.8118386.

K. B. Turrin · J. M. Trujillo ( $\square)$

University of Colorado Skaggs School of Pharmacy and Pharmaceutical Sciences, Aurora, CO, USA e-mail: Jennifer.trujillo@ucdenver.edu between DN scores and patient characteristics, glycemic control, and self-management behaviors.

Results: Average age was $52 \pm 15$ years, glycosylated hemoglobin (A1C) was $7.7 \% \pm 1.2 \%$ $(61 \mathrm{mmol} / \mathrm{mol})$, duration of diabetes was $28 \pm 15$ years, and duration of pump use was $3.4 \pm 1.3$ years. The average DNT-15 score was $87.5 \% \pm 18 \%$. Forty-three participants $(60 \%)$ scored $\geq 90 \%$ and 29 participants (40\%) scored $<90 \%$. Eighteen percent were unable to calculate the carbohydrate content from a nutrition label. Participants with lower DNT-15 scores had higher A1C levels $(8.0 \%$ vs. $7.5 \%, p=0.04)$, were older ( 58.3 vs. $47.7, p=0.003)$, were more likely to describe their diabetes self-care as poor $(p=0.04)$, and were less confident in using their pump features $(p=0.02)$ than those with higher DNT-15 scores.

Conclusion: Many patients on insulin pump therapy have deficiencies with DN which may be associated with older age and higher A1C levels.

Keywords: Continuous subcutaneous insulin infusion; Diabetes; Health numeracy; Insulin pump; Self-management
Abbreviations
A1C Glycosylated hemoglobin
BMI Body mass index
DNT-15 Diabetes Numeracy Test 


$\begin{array}{ll}\text { DSMQ } & \begin{array}{l}\text { Diabetes Self-Management } \\ \text { Questionnaire }\end{array} \\ \text { HL } & \text { Health literacy } \\ \text { HN } & \text { Health numeracy } \\ \text { IQR } & \text { Interquartile range } \\ \text { SD } & \text { Standard deviation }\end{array}$

\section{INTRODUCTION}

Over 90 million Americans have inadequate health literacy (HL) skills, and over 110 million have limited health numeracy (HN) skills [1]. Health literacy is defined as "the degree to which individuals can obtain, process, understand and communicate about health-related information needed to make informed health decisions" [2]. Health numeracy is the ability to understand and use numbers in daily life, and is associated with HL but requires distinct skills such as understanding measurement, estimation, time, logic, multistep operations, and identifying which math skills need to be applied to solve problems [3-7]. Diabetes numeracy (DN) is the ability to apply HN skills to solve problems and perform self-management tasks specific to diabetes care [8]. Adequate HL and DN skills are crucial in the management of diabetes, particularly for those on complex, intensive insulin therapy. While HL and DN may be related, patients with adequate HL skills may lack basic DN skills [8].

Previous studies in patients with diabetes indicated that low HL and DN have been associated with worse disease knowledge, poor medication adherence, and poorer glycemic control $[9,10]$. Most of the patients in these studies had type 2 diabetes and were not on intensive insulin regimens. To our knowledge, there are no data on the prevalence of low DN and its impact on glycemic control and diabetes self-management behaviors in patients on insulin pump therapy. In order for insulin pump therapy to be safe and effective, patients must participate in routine self-management activities that require adequate DN skills such as reading nutrition labels, estimating the carbohydrate content of food, interpreting fingerstick glucose readings, calculating insulin doses, applying carbohydrate to insulin ratios and insulin sensitivity factors, and evaluating data from their individual insulin pumps [11]. Therefore, the purpose of this study is to (1) assess DN levels of patients on insulin pump therapy and (2) explore the glycemic control and diabetes self-management behaviors of patients with different $\mathrm{DN}$ levels on insulin pump therapy.

\section{METHODS}

\section{Study Design}

This was an exploratory, observational, crosssectional study of the DN levels of patients on insulin pump therapy and the glycemic control and self-management behaviors of patients with different DN levels.

\section{Setting and Study Participants}

From May 2016 to November 2016, patients from one specialty endocrinology clinic within a university health system were identified weekly through clinic schedules and invited to participate during their regular clinic appointment. Participants could be included in the study if they had type 1 or type 2 diabetes, were between 18 and 80 years of age, were English speaking, and were on insulin pump therapy for at least 3 months. Exclusion criteria included a preexisting diagnosis of severe cognitive impairment, dementia, psychosis, or blindness, or a corrected visual acuity of 20/50 or worse using a Rosenbaum vision screener. Participants received compensation (a \$20 gift card) for participating in the study. The Colorado Multiple Institutional Review Board (COMIRB) through the University of Colorado Anschutz Medical Campus approved this study (protocol \#16-0195; initially approved on 3-18-2016). All procedures performed in studies involving human participants were in accordance with the ethical standards of the 1964 Declaration of Helsinki and its later amendments or comparable ethical standards. Written informed consent was obtained from all participants. 


\section{Study Procedures and Assessments}

This study involved a single clinic visit for each participant. Patients were invited to participate in the study at the beginning of their routine scheduled clinic visit. Once the routine clinic visit had concluded, the participants moved to a separate room to complete a DN test and two questionnaires. The estimated time needed to complete all study requirements was $30 \mathrm{~min}$, but time limits were not given.

Diabetes numeracy was assessed by administering the Diabetes Numeracy Test (DNT-15), a validated 15 -item test that evaluates diabetesrelated math and interpretive skills [12]. The DNT-15 is composed of word problems that require basic math calculations as well as application of those skills in the daily diabetes self-management setting, such as the interpretation of insulin dosing tables and nutrition labels [13]. The general guidelines for written administration of the DNT-15 were followed. All patients were given verbal instructions, a pencil, paper, and a calculator before starting the test. Patient performance on the DNT-15 was calculated as a percentage of questions answered correctly (score range: 0-100\%). Missing values were considered to be incorrect responses.

Diabetes self-management activities were assessed by administering the validated Diabetes Self-Management Questionnaire (DSMQ) [14]. The DSMQ asked the participant to rate their self-management through descriptive choices, and numbers were assigned to each description, where 1 = applies to me very much, $2=$ applies to me a considerable degree, $3=$ applies to me to some degree, and $4=$ does not apply to me. Additional self-management behaviors were obtained from electronic medical record data from the most recent clinic visit, including frequency of self-monitoring of blood glucose, frequency of infusion set placement, frequency of bolus dosing, and utilization of the bolus dose calculation function of the pump.

Participants also completed a general diabetes questionnaire to assess socioeconomic information and self-efficacy measures, including ethnicity, highest level of education, annual household income, prior diabetes education, and satisfaction and confidence with insulin pump use.

Glycemic control was assessed using the glycosylated hemoglobin (A1C), the 30-day glucometer download, and/or the 30-day insulin pump download from that day's clinic visit. If data were not available from that day's clinic visit, the most recent data found in the patient's electronic medical record was collected. Information gathered from the glucometer and pump downloads included the 30-day average glucose, the standard deviation (SD), the percentage of glucose readings within, above, and below the target range, and the proportion of blood glucose measurements $<3.88 \mathrm{mmol} / \mathrm{L}$.

Additional demographic and clinical information such as age, gender, duration of diabetes, and body mass index (BMI) was collected by reviewing electronic medical records.

Study data were collected and managed using REDCap electronic data capture tools hosted at the University of Colorado [15]. REDCap is a secure, web-based application designed to support data capture for research studies.

\section{Statistical Analysis}

All analysis was performed using the SAS 9.3 software package (SAS Institute, Inc., Cary, NC, USA). Descriptive statistics were calculated as the mean (SD) or median [interquartile range (IQR)], and the frequency and percentage were evaluated for categorical variables. Patients were categorized into two groups based on their DNT-15 scores (scores $\geq 90 \%$ and scores $<90 \%$ ). Participants in the $\geq 90 \%$ group answered 14 or 15 out of 15 questions correctly on the DNT-15 and were considered to have high or adequate DN skills. Participants in the $<90 \%$ group answered 13 or fewer out of 15 questions correctly on the DNT-15, indicating some level of deficiency in DN skills. Patient demographics, glycemic control outcomes, and self-management behaviors of patients in the two groups were compared. The chi-square test was used for categorical variables, the Wilcoxon rank sum test was used for continuous variables, and analysis of covariance (ANOVA) was used 
Table 1 Patient characteristics

\begin{tabular}{|c|c|c|c|c|}
\hline & $\begin{array}{l}\text { Total } \\
(n=72)\end{array}$ & $\begin{array}{l}\text { DNT-15 score }<90 \% \\
(n=29)\end{array}$ & $\begin{array}{l}\text { DNT-15 score } \geq 90 \% \\
(n=43)\end{array}$ & $p$ value \\
\hline Gender, no. (\%) & & & & 0.43 \\
\hline Female & $42(58.3)$ & $19(65.5)$ & $23(53.5)$ & \\
\hline Male & $30(41.7)$ & $10(34.5)$ & $20(46.5)$ & \\
\hline Race, no. (\%) & & & & 0.88 \\
\hline White not Hispanic & $65(90.3)$ & $26(89.7)$ & $39(90.7)$ & \\
\hline Other & $7(9.7)$ & $3(10.3)$ & $4(9.3)$ & \\
\hline Age, years (SD) & $52.0(14.9)$ & $58.3(14.9)$ & $47.7(13.7)$ & 0.003 \\
\hline BMI, $\mathrm{kg} / \mathrm{m}^{2}(\mathrm{SD})$ & $28.1(5.9)$ & $29.7(7.8)$ & $27.0(3.8)$ & 0.06 \\
\hline Duration of diabetes, years (SD) & $27.3(14.9)$ & $29.6(16.2)$ & $25.8(13.9)$ & 0.29 \\
\hline Duration of pump use, years (SD) & $3.4(1.3)$ & $3.2(1.1)$ & $3.5(1.4)$ & 0.34 \\
\hline \multicolumn{5}{|l|}{ Education level, no. (\%) } \\
\hline College degree or higher & $46(63.9)$ & $12(41.4)$ & $34(79.1)$ & \\
\hline High school graduate/equivalent & $24(33.3)$ & $15(51.7)$ & $9(20.9)$ & \\
\hline 12th grade, no diploma & $2(2.8)$ & $2(6.9)$ & 0 & \\
\hline \multicolumn{5}{|l|}{ Household income, no. (\%) } \\
\hline Less than $\$ \$ 39,999$ & $13(18.1)$ & $5(17.2)$ & $8(18.6)$ & \\
\hline$\$ 40,000$ to $\$ 99,999$ & $24(33.3)$ & $9(31.0)$ & $15(34.9)$ & \\
\hline$\$ 100,000$ or more & $30(41.7)$ & $11(37.9)$ & $19(44.2)$ & \\
\hline
\end{tabular}

for ordinal data. The level of significance was predefined as $p<0.05$. Because of the exploratory, observational nature of the study, a sample-size calculation was not performed. A sample-size of 75 was targeted based on the intention that this study would serve as a smallscale pilot study prior to a subsequent larger study.

\section{RESULTS}

\section{Demographics}

Seventy-two participants were enrolled in the study. The average age was $52 \pm 14.9$ years, the average A1C was $7.7 \% \pm 1.2 \%(61 \mathrm{mmol} / \mathrm{mol})$, the duration of diabetes was $27.3 \pm 14.9$ years, and the duration of insulin pump use was
$3.4 \pm 1.3$ years. Forty-two participants $(58.3 \%)$ were female. Sixty-five participants $(90.3 \%)$ selfidentified their race as White, not Hispanic (Table 1). All patients had type 1 diabetes.

\section{DNT-15 Performance}

The median score on the DNT-15 was $93.3 \%$ (IQR 18.5). The average score on the DNT-15 was $87.5 \%$ (SD 18). Forty-three participants $(60 \%)$ scored $\geq 90 \%$, indicating adequate $\mathrm{DN}$ skills; 29 participants (40\%) scored <90\%, indicating some deficiency in DN skills. Of note, 14 participants $(19 \%)$ scored $<76 \%$, indicating more limited DN skills. The most common questions missed on the DNT-15 related to calculating carbohydrate content from a nutrition label (18\% answered incorrectly), assessing how to adjust diet based on exercise (14\% answered 
incorrectly), calculating an insulin dose based on both carbohydrate amount and blood glucose level (19\% answered incorrectly), and interpreting insulin dose titration instructions (26\% answered incorrectly).

\section{DNT-15 Score and Glucose Variables}

Participants who scored higher on the DNT-15 had lower A1C levels (7.5\% in DNT-15 scores $\geq 90 \%$ vs. $8.0 \%$ in DNT-15 scores $<90 \%$, $p=0.04$, Table 2). Participants with higher DNT-15 scores had more 30-day glucometer readings below goal compared to participants with lower DN scores $(7.8 \%$ vs. $3.9 \%, p=0.03)$.

\section{DNT-15 Score and Patient Characteristics}

Participants who scored higher on the DNT-15 were younger than those with lower DNT-15

Table 2 Glycemic control and DNT-15 scores

\begin{tabular}{|c|c|c|c|}
\hline & $\begin{array}{l}\text { DNT-15 } \\
\text { score } \\
<90 \% \\
(n=29)\end{array}$ & $\begin{array}{l}\text { DNT-15 } \\
\text { score } \geq 90 \% \\
(n=43)\end{array}$ & $p$ value \\
\hline $\mathrm{A} 1 \mathrm{C}, \%(\mathrm{SD})$ & $8.0(1.4)$ & $7.5(0.9)$ & 0.04 \\
\hline $\begin{array}{l}\mathrm{A} 1 \mathrm{C}, \mathrm{mmol} / \mathrm{mol} \\
\quad(\mathrm{SD})\end{array}$ & $64.0(11.2)$ & $58.0(7.0)$ & 0.04 \\
\hline $\begin{array}{l}\text { 30-day glucose } \\
\text { average, mmol/L } \\
(\mathrm{SD})^{\mathrm{a}}\end{array}$ & $10.9(2.6)$ & $10.0(2.5)$ & 0.14 \\
\hline $\begin{array}{l}\text { 30-day glucose } \\
\text { standard } \\
\text { deviation, mmol/ } \\
\mathrm{L}(\mathrm{SD})^{\mathrm{a}}\end{array}$ & $4.7(1.6)$ & $4.0(1.4)$ & 0.06 \\
\hline $\begin{array}{l}\text { Readings above } \\
\text { goal, } \%(\mathrm{SD})^{\mathrm{a}}\end{array}$ & $62.5(19.9)$ & $55.0(21.0)$ & 0.15 \\
\hline $\begin{array}{l}\text { Readings below } \\
\text { goal, } \%(\mathrm{SD})^{\mathrm{a}}\end{array}$ & $3.9(4.1)$ & $7.8(8.6)$ & 0.03 \\
\hline $\begin{array}{l}\text { Readings within } \\
\text { goal, \% }(\mathrm{SD})^{\mathrm{a}}\end{array}$ & 33.7 (18.7) & $37.5(19.2)$ & 0.42 \\
\hline
\end{tabular}

scores (average age 47.7 years in DNT-15 scores $\geq 90 \%$ vs. 58.3 years in DNT-15 scores $<90 \%$, $p=0.003$; Table 1). Participants who scored higher on the DNT-15 appeared to have a higher level of education than those who scored lower, but statistical analysis was not performed due to the small sample size. No significant trends between groups were found in regards to race, BMI, or household income.

\section{DNT-15 Score and Pump-Related Self- Management Behaviors}

The analysis of pump-related self-management behaviors and DNT-15 score showed that participants with higher DN scores were associated with more frequent use of average manual boluses per day (2.3 per day in DNT-15 score $\geq 90 \%$ group vs. 0.6 per day in DNT-15 score $<90 \%, p=0.03$ ) (Table 3 ). There were no other significant differences in pump-related behaviors between groups.

\section{DNT-15 Score and Self-Management Behaviors}

The analysis of the DSMQ and DNT-15 scores showed that patients with lower DN scores associated more personal responsibility with the statement "My diabetes self-care is poor" (DNT$15<90 \% 3.24$ vs DNT-15 $\geq 90 \% 3.65$, $p=0.04)$. Patients with lower DN scores also associated more with the statements "I avoid physical activity, although it would improve my diabetes" (DNT-15 <90\% 3.14 vs DNT-15 $\geq 90 \% 3.65, p=0.01$ ) and "I tend to skip planned physical activity" (DNT-15 < 90\% 3.33 vs. DNT-15 $\geq 90 \% 3.74, p=0.01$ ). All other analyses of DSMQ and DNT-15 score showed no significant differences between groups (Table 4).

\section{DNT-15 Score and Self-Efficacy}

On a scale from 0 to 100 , with 100 being fully confident, there was no significant difference between groups when participants were asked about their general level of confidence in managing diabetes with an insulin pump (86 in participants with DNT-15 score $\geq 90 \%$ vs. 84 in 
Table 3 Pump-related self-management behaviors and DNT-15 scores

\begin{tabular}{|c|c|c|c|}
\hline & $\begin{array}{l}\text { DNT-15 } \\
\text { score }<90 \% \\
(n=29)\end{array}$ & $\begin{array}{l}\text { DNT-15 } \\
\text { score } \\
\geq 90 \% \\
(n=43)\end{array}$ & $p$ value \\
\hline $\begin{array}{l}\text { Average manual } \\
\text { boluses per day }\end{array}$ & $0.6(1.1)$ & $2.3(3.3)$ & 0.04 \\
\hline $\begin{array}{l}\text { Average bolus } \\
\text { wizard events per } \\
\text { day }\end{array}$ & $4.8(1.9)$ & $4.2(2.6)$ & 0.40 \\
\hline $\begin{array}{l}\text { Percent of boluses } \\
\text { overridden }\end{array}$ & $18.9(22.4)$ & $24.1(26.7)$ & 0.50 \\
\hline $\begin{array}{l}\text { Percent of boluses } \\
\text { with correction }\end{array}$ & $67.8(23.9)$ & $64.4(21.4)$ & 0.62 \\
\hline $\begin{array}{l}\text { Average number of } \\
\text { target glucose } \\
\text { settings }\end{array}$ & $2.1(0.9)$ & $1.9(0.9)$ & 0.68 \\
\hline $\begin{array}{l}\text { Average number of } \\
\text { basal settings }\end{array}$ & $4.7(1.6)$ & $4.5(1.7)$ & 0.72 \\
\hline $\begin{array}{l}\text { Average number of } \\
\text { correction factor } \\
\text { settings }\end{array}$ & $2.2(1.5)$ & $2.6(3.2)$ & 0.48 \\
\hline $\begin{array}{l}\text { Average number of } \\
\text { C:I ratio settings }\end{array}$ & $2.5(1.1)$ & $2.4(1.1)$ & 0.59 \\
\hline $\begin{array}{l}\text { Average blood } \\
\text { glucose readings } \\
\text { per day }\end{array}$ & $4.1(1.5)$ & $4.6(4.5)$ & 0.6 \\
\hline $\begin{array}{l}\text { Average frequency } \\
\text { of infusion set } \\
\text { placement, days }\end{array}$ & $3.8(0.9)$ & $3.8(0.6)$ & 0.91 \\
\hline
\end{tabular}

participants with DNT-15 score $<90 \%$, $p=0.49$ ). However, when asked more specifically about pump features, participants with higher DNT-15 scores expressed more confidence in using their pump features than patients with lower DNT-15 scores (87 vs. 75 , $p=0.02$ ). There was also no significant difference between groups in participant ratings of insulin pump satisfaction, self-perceived understanding of how to use their insulin pump, or receipt of sufficient insulin pump training from a diabetes educator.

\section{DISCUSSION}

This study suggests that many patients on insulin pump therapy managed at a single specialty endocrinology clinic had some deficiency in DN skills. Although the median and mean DNT-15 scores were both reasonably high (93.3\% and $87.5 \%$, respectively), deficiencies in DN were still present. In addition, $19 \%$ of our patient population achieved a score of $<76 \%$, indicating limited DN skills, which could have significant implications for the way in which they manage their insulin pump therapy. Importantly, almost one in five patients were unable to calculate the carbohydrate content of a food item when given a nutrition label-a task that insulin pump users should perform daily. Also, approximately one in five patients could not calculate an insulin bolus dose accounting for both carbohydrate intake and glucose level. This highlights a concern that some patients may be relying solely on the pump's bolus dose calculator and are unable to perform dose calculations independently.

The occurrence and severity of low DN does seem to be better in our patient population compared to other studied populations. In a study conducted by Cavanaugh et al., the median DNT-15 score was $65 \%$ in a population of patients with type 1 or type 2 diabetes in either a primary care or diabetes clinic, which was significantly lower than the median DNT15 score of $93.3 \%$ in our study population [10]. This may be because our population was solely in a single, specialty endocrinology clinic and included patients with type 1 diabetes. In a study conducted by Zaugg et al., patients who received care from a specialist at a diabetes center had higher DN levels than patients who received care from a primary care provider, and patients with type 1 diabetes had higher DN levels compared to patients with type 2 diabetes [16].

This study also suggests that low diabetesrelated DN skills may be associated with poorer glycemic control, as well as some worse 
Table 4 Diabetes self-management questionnaire (DSMQ) results and DNT-15 scores

\begin{tabular}{|c|c|c|c|}
\hline & $\begin{array}{l}\text { DNT-15 score }<90 \% \\
(n=29), \text { score }(\mathrm{SD})\end{array}$ & $\begin{array}{l}\text { DNT-15 score } \geq 90 \% \\
(n=43), \text { score }(\mathrm{SD})\end{array}$ & $p$ value \\
\hline I check my blood sugar levels with care and attention & $1.48(0.63)$ & $1.5(0.63)$ & 0.91 \\
\hline $\begin{array}{l}\text { The food I choose to eat makes it easy to achieve optimal } \\
\text { blood sugar levels }\end{array}$ & $2.24(0.74)$ & $2.30(0.76)$ & 0.74 \\
\hline $\begin{array}{l}\text { I keep all doctors' appointments recommended for my } \\
\text { diabetes treatment }\end{array}$ & $1.14(0.44)$ & $1.19(0.54)$ & 0.69 \\
\hline $\begin{array}{l}\text { I take my diabetes medications (e.g., insulin boluses) as } \\
\text { prescribed }\end{array}$ & $1.17(0.38)$ & $1.07(0.26)$ & 0.19 \\
\hline $\begin{array}{l}\text { Occasionally I eat lots of sweets or other foods rich in } \\
\text { carbohydrates }\end{array}$ & $2.86(0.76)$ & $2.58(0.75)$ & 0.14 \\
\hline I record my blood sugar levels regularly & $2.39(1.17)$ & $2.21(1.17)$ & 0.52 \\
\hline I tend to avoid diabetes-related doctors' appointments & $4(0)$ & $3.98(0.15)$ & 0.42 \\
\hline $\begin{array}{l}\text { I do regular physical activity to achieve optimal blood sugar } \\
\text { levels }\end{array}$ & $2.46(1.07)$ & $2.49(0.85)$ & 0.92 \\
\hline $\begin{array}{l}\text { I strictly follow the dietary recommendations given by my } \\
\text { doctor or diabetes specialist }\end{array}$ & $2.24(0.83)$ & $2.47(0.73)$ & 0.23 \\
\hline $\begin{array}{l}\text { I do not check my blood sugar levels frequently enough as } \\
\text { would be required for achieving good blood glucose control. }\end{array}$ & $3.59(0.82)$ & $3.51(0.69)$ & 0.68 \\
\hline $\begin{array}{l}\text { I avoid physical activity, although it would improve my } \\
\text { diabetes }\end{array}$ & $3.14(0.88)$ & $3.65(0.68)$ & 0.01 \\
\hline $\begin{array}{l}\text { I tend to forget to take or skip my diabetes medications (e.g., } \\
\text { insulin boluses) }\end{array}$ & $3.55(0.74)$ & $3.70(0.46)$ & 0.31 \\
\hline $\begin{array}{l}\text { Sometimes I have real "food binges" (not triggered by } \\
\text { hypoglycemia) }\end{array}$ & $3.34(0.86)$ & $3.37(0.75)$ & 0.89 \\
\hline $\begin{array}{l}\text { Regarding my diabetes care, I should see my medical provider } \\
\text { more often }\end{array}$ & $3.62(0.68)$ & $3.61(0.69)$ & 0.95 \\
\hline I tend to skip planned physical activity & $3.33(0.78)$ & $3.74(0.49)$ & 0.01 \\
\hline My diabetes self-care is poor & $3.24(0.99)$ & $3.65(0.64)$ & 0.04 \\
\hline
\end{tabular}

Scores are averages based on a four-point scale where 1 = applies to me very much; 2 = applies to me a considerable degree; $3=$ applies to me to some degree; $4=$ does not apply to me

perceived self-efficacy and self-management behaviors in patients on insulin pump therapy. Our findings are generally consistent with other studies that have shown similar associations in patients with diabetes $[8,10,17]$, but, to our knowledge, our study is the first look into this potential association in patients specifically on insulin pump therapy.

Although one might speculate that patients with low DN would use an insulin pump differently than those with higher DN, we did not see trends indicating differences in pump-related self-management behaviors between DN 
groups. One interesting finding was that participants with high $\mathrm{DN}$ had greater use of manual boluses, which may indicate more comfort with performing dose calculations without the help of the pump's bolus dose calculator.

This study also found that individuals who scored lower on the DNT-15 were older. Similar studies have associated lower DN levels with age $[8,10]$, indicating that as patients grow older their ability to effectively manage their diabetes may diminish. Additionally, older patients may pay less attention to serving size, thereby decreasing the accuracy of their nutrition calculations [18], which could increase the risk of administering an incorrect dose of insulin. Older patients are also at an increased risk of cognitive dysfunction [19], and are more likely to report worse adherence to diabetes care [20]. Providers should recognize the impact that age may have on DN skills, diabetes self-management, and effective insulin pump use.

There are several limitations of our study. First, conducting the study at a single, academic, specialty endocrinology clinic limits the diversity of our patient population, so the findings may not be generalizable to a larger population. Several studies have indicated that low education level and minority populations have been associated with lower DN levels and poorer glycemic control $[8,21]$, but these populations were not well represented in this study. Of note, even though the participants in our study had high education levels, were mostly White, not Hispanic, and were generally well-managed patients under a high level of specialized care, low DN was still identified. This suggests that $\mathrm{DN}$ is a widespread issue that affects more than minority or underserved populations. Second, this study was designed as an exploratory, observational, cross-sectional survey that was performed to initially explore possible relationships, so no conclusions on causation can be made. Our study also had a small sample size, which limits the statistical analysis. Additionally, the DNT-15 includes several questions geared towards a more general diabetes population (e.g., those on insulin injections or oral medications), which could limit the validity of the tool in our patient population. Last, there was limited availability of self-management data based on the download capability of the insulin pump type and brand.

Our study reinforces the need to identify and address DN in the diabetes population. Health literacy and numeracy focused interventions and communication strategies have been developed for a more generalized diabetes population and have been shown to improve selfefficacy and diabetes self-management behaviors [22-26]. Such strategies should also be considered in patients on insulin pump therapy.

Adequate DN skills are crucial to patients' ability to process and act on data related to their insulin pump [11]. These requirements will expand as insulin pump technology continues to advance and with the incorporation of continuous glucose monitoring.

Although most patients on insulin pump therapy receive extensive education and training on numeracy-related topics, it is unknown how effective this education is or if the education is delivered at an appropriate level to ensure proper use. Currently, educational materials provided to patients with diabetes are lacking in readability, especially in relation to numeracy [27]. For example, the education workbooks provided by the three most common insulin pump manufacturers require numeracy skills well above the average adult to understand their content [28]. DN skills should be assessed in all patients on insulin pump therapy, and education should be delivered at an appropriate level to ensure safe and effective use $[17,27,28]$. Further research is needed on the relationships between DN and the safety and efficacy of insulin pump usage.

\section{CONCLUSION}

Deficiencies in DN skills are present in patients on insulin pump therapy, even with a high level of care in a specialty endocrinology clinic. This study suggests that some patients with diabetes on insulin pump therapy cannot complete DN self-management tasks such as counting carbohydrates or determining appropriate insulin dosing. In this study, participants with lower 
DN scores had higher A1C levels, were older, were more likely to describe their diabetes selfcare as poor, and had less confidence in their ability to use the features of their insulin pump. Further research in larger, more diverse populations is needed to determine DN skills in patients on insulin pump therapy and to identify possible associations with patient characteristics, glycemic control, and selfmanagement behaviors.

\section{ACKNOWLEDGEMENTS}

We thank the participants of this study.

Funding. The University of Colorado Skaggs School of Pharmacy and Pharmaceutical Sciences Department of Clinical Pharmacy Internal Seed Grant and Doctor of Pharmacy Student Research Grant funded this study as well as the article processing charges.

Authorship. All named authors meet the International Committee of Medical Journal Editors (ICMJE) criteria for authorship for this article, take responsibility for the integrity of the work as a whole, and have given their approval for this version to be published.

Disclosures. The authors Kali B. Turrin and Jennifer M. Trujillo have nothing to disclose.

Compliance with Ethics Guidelines. The Colorado Multiple Institutional Review Board (COMIRB) through the University of Colorado Anschutz Medical Campus approved this study (protocol \#16-0195; initially approved on 3-182016). All procedures performed in studies involving human participants were in accordance with the ethical standards of the 1964 Declaration of Helsinki and its later amendments or comparable ethical standards. Written informed consent was obtained from all participants.

Data Availability. The datasets obtained and/or analyzed during the current study are available from the corresponding author on reasonable request.
Open Access. This article is distributed under the terms of the Creative Commons Attribution-NonCommercial 4.0 International License (http://creativecommons.org/licenses/ by-nc/4.0/), which permits any noncommercial use, distribution, and reproduction in any medium, provided you give appropriate credit to the original author(s) and the source, provide a link to the Creative Commons license, and indicate if changes were made.

\section{REFERENCES}

1. Kutner M, Greenberg E, Baer J. A first look at the literacy of America's adults in the 21st century. Washington, DC: National Center for Education Statistics, US Department of Education; 2005.

2. Berkman ND, Davis TC, Mccormack L. Health literacy: what is it? J Health Commun. 2010;15(Suppl 2):9-19.

3. Lipkus IM, Peters E. Understanding the role of numeracy in health: proposed theoretical framework and practical insights. Health Educ Behav. 2009;36(6):1065-81.

4. Rothman RL, Housam R, Weiss H, et al. Patient understanding of food labels: the role of literacy and numeracy. Am J Prev Med. 2006;31(5):391-8.

5. Rothman RL, Montori VM, Cherrington A, et al. Perspective: the role of numeracy in health care. J Health Commun. 2008;13:583-95.

6. Cavanaugh KL. Health literacy in diabetes care: explanation, evidence and equipment. Diabetes Manag. 2011;1(2):191-9.

7. Montori VM, Rothman RL. Weakness in numbers. The challenge of numeracy in health care. J Gen Intern Med. 2005;20:1071-2.

8. Schillinger D, Grumbach K, Piette J, et al. Association of health literacy with diabetes outcomes. J Am Med Assoc. 2002;288:475-82.

9. Osborn CY, Cavanaugh K, Wallston KA, et al. Diabetes numeracy: an overlooked factor in understanding racial disparities in glycemic control. Diabetes Care. 2009;32(9):1614-9.

10. Cavanaugh K, Huizinga MM, Wallston KA, et al. Association of numeracy and diabetes control. Ann Intern Med. 2008;148:737-46. 
11. Kerr David. Poor numeracy: the elephant in the diabetes technology room. J Diabetes Sci Technol. 2010;4(6):1284-7.

12. Huizinga MM, Elasy TA, Wallston KA, et al. Development and validation of the Diabetes Numeracy Test (DNT). BMC Health Serv Res. 2008;8:96.

13. Vanderbilt University. THE DNT15: a shortened versionof theDiabetes Numeracy Test (DNT). Nashville, TN: Vanderbilt University; 2007. http:// www.mc.vanderbilt.edu/documents/CDTR/files/dia betes-numeracy-test-15.pdf. Accessed 15 Nov 2017.

14. Schmitt A, Gahr A, Hermanns N, et al. The Diabetes Self-Management Questionnaire (DSMQ): development and evaluation of an instrument to assess diabetes self-care activities associated with glycaemic control. Health Qual Life Outcomes. 2013;11:138.

15. Harris PA, Taylor R, Thielke R, et al. Research electronic data capture (REDCap) - a metadata-driven methodology and workflow process for providing translational research informatics support. J Biomed Inform. 2009;42(2):377-81.

16. Zaugg SD, Dogbey G, Collins K, et al. Diabetes numeracy and blood glucose control: association with type of diabetes and source of care. Clin Diabetes. 2014;32:152-7.

17. Marden S, Thomas PW, Sheppard ZA, et al. Poor numeracy skills are associated with glycaemic control in type 1 diabetes. Diabet Med. 2012;29(5):662-9.

18. Miller LM, Applegate E, Beckett LA, et al. Age difference in the use of serving size information on labels: numeracy or attention? Public Health Nutr. 2017;20(5):786-96.

19. Tomlin A, Sinclair A. The influence of cognition on self-management of type 2 diabetes in older people. Psychol Res Behav Manag. 2016;9:7-20.
20. Feil DG, Pearman A, Victor T, et al. The role of cognitive impairment and caregiver support in diabetes management of older outpatients. Int J Psychiatry Med. 2009;39(2):199-214.

21. Trief PM, Cibula D, Rodriguez E, et al. Incorrect insulin administration: a problem that warrants attention. Clin Diabetes. 2016;34(1):25-33.

22. Cavanaugh K, Wallston KA, Gebretsadik T, et al. Addressing literacy and numeracy to improve diabetes care. Diabetes Care. 2009;32(12):2149-55.

23. White RO, Wolff K, Cavanaugh KL, et al. Addressing health literacy and numeracy to improve diabetes education and care. Diabetes Spectr. 2010;23(4):238-43.

24. Wolff K, Cavanaugh K, Malone R, et al. The Diabetes Literacy and Numeracy Education Tool Kit (DLNET): materials to facilitate diabetes education and management in patients with low literacy and numeracy skills. Diabetes Educ. 2009;35(2):233-6 (238-41, 244-5).

25. Wolff K, Chambers L, Bumol S, et al. The PRIDE (partnership to improve diabetes education) toolkit. Diabetes Educ. 2016;42:23-33.

26. Inoue M, Takahashi M, Kai I. Impact of communicative and critical health literacy on understanding of diabetes care and self-efficacy in diabetes management: a cross-sectional study of primary care in Japan. BMC Fam Pract. 2013;23(14):40.

27. Joram E, Roberts-Dobie S, Mattison SJ, et al. The numeracy demands of health education information: an examination of numerical concepts in written diabetes materials. Health Commun. 2012;27(4):344-55.

28. Kerr D, Marden S. Numeracy and insulin pump therapy. Diabet Med. 2010;27(6):730-1. 